\title{
FLAWS IN THE SOCIAL MANNERS OF CZECH MANAGERS
}

\author{
Gullová, S.
}

We expect businesspeople, managers and representatives to know and apply Central European rules of etiquette. When travelling abroad or dealing with people from different countries the guest, of course, adjusts their behavior according to their host; however, only as far as their own etiquette allows. However, many Czech managers are ignorant of the rules of their own etiquette. Nowadays, knowledge of etiquette is becoming an economic must. It is evident that in order to gain or retain a job or be promoted one must abide by its rules. Companies no longer accept undue behavior on the side of their employees or permit such behavior to harm the working atmosphere within the company. The more the professional qualification of employees evens out, the more their manners and neat appearance gain in importance. Significant deficiencies in this respect are apparent especially in dealing with foreigners. On an international level, perfect manners are imperative.

JEL Classification: M12, M14

\section{Introduction}

After the political changes in 1989, many people believed that in social interaction anything was acceptable. Quite a few people continue to think so today. It is not the aim of this paper to uncover the causes of this phenomenon; this is up to psychologists, historians and political scientists. Loose morals, vulgarity, unwillingness to comply with certain rules and standards are being associated with the previous era. Today, however, this excuse is no longer acceptable. The nearly 20 years of democratic development of society has given everyone a chance to get rid of any aspect of social interaction and manners typical for the previous society they disapproved of. Another population group believes the rules of social intercourse to be obsolete. They argue that the way they treat others and the way they dress or look are nobody else's business. Unfortunately, such views are still shared by quite a few people engaged in economics and politics, who should represent the elite. Guth-Jarkovsky (1924) says, in short, that what one has inside should be reflected on the outside. People who cannot behave, can then hardly require good manners from others.

Currently, the low standard of social behavior in the Czech Republic is actually acknowledged. In a way, we can speak of a certain renaissance to social behavior in our country. Many companies, entrepreneurs and organizations realize that there is room for improvement and purposefully seek to ensure that their behavior and actions do not differ from those of their more experienced and foreign partners. Professional behavior is required in all aspects of modern life. In addition to factual knowledge of a topic and language skills in case of contact with a foreign partner, professional behavior is also required in demeanor, in manners. In serious business, certain rules are applied to the formal aspects of the interaction. These rules must be known and adhered to. They relate e.g. to meetings procedures, greetings, introductions, formal address, attire, table manners, talking on the phone, etc. Compared to Guth-Jarkovsky's times, current social behavior is less formalized. Fixed codes of conduct are, however, fighting their way back through the corporate culture that is emerging in the Czech Republic, especially through the influence of foreign companies.

Nowadays, being familiar with etiquette is primarily an economic necessity for individuals - in order to step up the career ladder, land a job or keep it - and for enterprises - to distinguish themselves from the competition and sell more of their products. This is illustrated by a recent survey of the consulting firm Goworr Consulting (CGC) among 600 managers in the EU (CGC, 2007). 
According to the survey, $87 \%$ of managers see a direct causality between personal professional success and courteous demeanor. Almost three quarters of managers confirm that personal behavior affects the negotiation process and business results.

It is certainly not merely a question of appearance. Enterprises no longer tolerate negotiations failing due to a manager's improper conduct or for a manager's behavior to distort the working atmosphere in a company. Many of our managers are not willing to respect and tolerate a foreign culture. The study „Enterprise 2010“carried out by the consulting agency Ernst and Young in the Czech Republic - states that the key skill of a future manager is by far not only their expertise but also their behavior, demeanor and ability to adapt to people from other cultures (Gullova, 2011). This article presents a review of the largest gaps in the knowledge of business etiquette in the Czech Republic.

\section{Greeting}

The mere greeting seems to cause a lot of problems for some Czech managers. An inappropriate greeting can influence the social life of a person and even negatively impact one's success in the workplace and, above all, in the world of business. One of the worst mistakes would be not to return the greeting. Welcome and farewell greetings are an indispensable ceremony and an absolute matter of course, especially in business and diplomatic interactions. According to Guth- Jarkovsky, "A greeting in the general sense is the most simple, common and widespread social act being an external expression of politeness, attention, friendship and affection, gratefulness, respect and admiration, eventually even subordination" (Guth-Jarkovsky, 1924). Not returning an offered greeting thus belongs among the worst mistakes.

Each culture in the world has come up with its own way of greeting and the respective parties also keep different levels of distance from each other. Globally, there are also many other differences. In some cultures, greetings up to present days include even spitting (e.g. in a large part of China, India, etc.). The most common way of greeting nowadays is shaking hands. The person with lower social precedence never imposes their hand on the more distinguished person, instead they wait for the person with social precedence to extend their hand first. The host always extends his/her hand first and welcomes everyone as they arrive - unfortunately, this rule is not as automatically kept as it should be, even on the highest levels. The intensity of the handshake differs from country to country. In some countries they exchange handshakes on every occasion (e.g. Germany, France); in others countries hands are shook only occasionally and even during introductions shaking hands is often omitted (e.g. Great Britain). In still other countries, it is only men who shake hands among themselves (e.g. the Arab countries), yet others greet themselves with a bow (e.g. the Japanese) etc. When meeting people from countries where shaking hands is not common, we should not force them to do it, especially the women.

\section{Introduction of persons}

An introduction is a ceremony common in the professional as well as personal life. In our country, the standards of introduction lag behind the common way in many European countries. Nevertheless, it is during introductions that first impressions are created. However, many Czech managers are ignorant of the fact that it is more appropriate to have someone introduce us. In business environments, a woman can introduce herself to men and women; however, in social intercourse, she presents herself to women but always has someone introduce her to men. At the beginning of a business meeting, every person present should be introduced.

\section{Exchange of business cards}

The exchange of business cards makes part of introductions and meetings in business intercourse. Practical experience reveals that it is particularly in the use and quality of business cards that Czech managers have potential for improvement. For professional purposes, it is essential nowadays to have business cards in various language versions. It is these "translated" business cards that show most need for improvement, especially in the use of academic titles and ranking in the company hierarchy. The recommendation to Czech managers is to omit their academic titles on their international (as opposed to Czech) business cards. Another rather frequent mistake rarely committed elsewhere in the world is the translating of names, especially first names, or the inadvisable translation of addresses or names of towns. Even the quality, appearance and use of business cards may vary territorially. Czech business cards should list the name before the surname.

Business cards are handed over either during the introductory ceremony or, if the introduction is incidental, before the farewell, especially if we intend to pursue a personal or professional relationship with the other person or company. Business cards should also be enclosed in any offers or marketing materials sent out. At ordinary business meetings, business cards are exchanged by all participants at the very beginning of the negotiation. They are never tossed across the table (as is 
unfortunately often the case in the Czech Republic), but handed over from hand to hand. We always take a look at the business card received and express gratitude. It is disrespectful to stuff the business card immediately into the pocket. It is also abhorrent to cross anything out, overwrite or in any other way change the information on a business card. Business cards must always be clean and creaseless.

\section{Addressing people}

When addressing people we can basically use the following four alternatives: name, surname, title or function. Looking abroad we can find a huge variety of customs, not only between regions and language zones but also between countries which are linguistically, territorially or even culturally related. We must pay close attention to becoming familiar with the contemporary rules of addressing. We are used to the use of titles in the Czech Republic; however, we often make serious mistakes when addressing foreigners. University degree "inženýr" does not necessarily translate as engineer and may not translate at all in many countries. A US shareholder is not referred to as Mr. President even if this is the function listed on his business card. Lawyers are not addressed as "doctor" in Anglo-Saxon countries. In some countries, it is common to address the partner with a higher function than the one they actually hold, etc. As academic titles are used less and less, I recommend using the professional function.

\section{Written communication and telephone contact}

Due to technological development, written communication has also evolved in form as well as in substance. The advantage of the use of modern technologies in communication is that it enables perfect layout as well as legibility. Evidently, we are recently witnessing a trend in business and similar correspondence toward a factual approach with a decreasing amount of formalities and the most commonly used venue is e-mail. E-mail allows individuals, companies and institutions to communicate all around the world and has a number of other advantages: it is fast, cheap and relatively reliable. However, even e-mail has its rules of conduct; they surged in the $90 \mathrm{~s}$ as part of the so-called netiquette. It includes the rules of conduct on the Internet. The underlying idea of netiquette is voluntariness, as its rules are not binding and should serve rather as recommendations. In addition, the need to observe the rules of netiquette is subject to the fact that in electronic communication the user often only knows their communication partner by their Internet or e-mail address and their contact is limited to the computer screen. All other aspects such as external appearance, attire, behavior, conduct, body language etc. remain unknown to the other party. Attention must be paid to the use of appropriate acronyms, emoticons and to other recommendations regarding the use of electronic mail so as to prevent violations of netiquette.

Telephone contact also has its own set of rules, but they can only be traced over decades. The same rules also apply for phone calls over the Internet, for the use of mobile phones and answering machines or for sending of text messages. A common phone conversation can be broken down into three segments: commencement, the substance itself and conclusion. Practical experience has shown that Czech managers often do not even know who should be the one to end a phone call - the caller or the called party. They are also often criticized for the use of mobile phones e.g. during negotiations or social events. We are censured to use our mobile phones as jewels which we like to show-off during negotiations and that even during negotiations we keep monitoring our phones in case someone should call. The rule for using mobile phones is: during negotiations give your full and undivided attention to your guest, do not talk over the phone with your family members, take care of any documents or send text messages etc. If possible, give notice to your secretary not to put through any calls. If we are expecting an urgent call, we must keep the length of the conversation to a minimum and offer our guests an apology as well as an explanation. Mobile phones should stay switched off during negotiations, as well as during important private visits, at the doctors, in hospitals, or during social and cultural events. Phones are inappropriate for condoling or for expressing one's sympathy. When sending a text message, it is important to always double-check the recipient. Even highly-ranked people have been known to have sent orders, e.g. suspensions from the office, to the wrong recipients by mistake.

\section{Organization and preparation of a business negotiation}

If the negotiation is taking place on our "home ground" we have the psychological advantage of our home settings. Any time we need we can include more specialists in the negotiation, exchange the members of our team, and use our own technique; we are the ones to propose the course and the agenda of the meeting, and we decide on the timing of the negotiation as it suits us.

The general rule is that the travelling party is the one more interested in the deal. Negotiations which take place on neutral grounds or in a third country (e.g. on a trade fair) eliminate the advantages and disadvantages of hosts and 
guests. They also make the stay equally cost consuming for both parties. Unfortunately, Czechs belong among the group of business people who like to travel and mostly prefer dealing abroad. They are not capable of taking advantage of negotiating on their "home grounds" and are not skilled at preparing a negotiation on their grounds well.

These days, all meetings must be booked in advance. By no means can we demand an instant reception. Everybody has a formerly arranged program and everybody also needs time to prepare for the meeting. The meeting can be proposed by any of the parties in various forms: in writing (by mail, e-mail) or orally (e.g. by phone). Meetings are often arranged by the employees themselves or by their secretariat. The timing of negotiations with partners from abroad is determined at least a fortnight in advance. The timing is usually proposed by the hosting party, the guest is expected to accommodate; thus, it is the host who chooses the time of the meeting. In Europe, most meetings take place around 10 A.M. or around 3 - 4 P.M. We need to take into consideration the local customs when dealing with a foreign partner or in a foreign country. These may include different working days within a week (e.g. in Arab countries), state and religious holidays, religious customs, unwillingness to work and hold meetings after working hours (e.g. Germany), unwillingness to receive visitors and hold meetings on Fridays (especially Friday afternoon) or on Monday mornings. In some countries, partners will prefer to hold meetings in the evening (often at somebody's home) and they may end at very late hours. If the meeting has been set for 12 noon (usual in some countries), we cannot automatically interpret this as an invitation for lunch. In the Czech Republic, it is not advisable to set meetings for earlier than 9 - 10 A.M. Meetings and negotiations should also not be combined with vacations. Surprisingly many of our managers are not aware of the fact that it is not wise to plan meetings on the day of our guests' arrival, especially if they are arriving from a distant country. We need to allow for rest and acclimatization; time management isn't concerned only with the time of the meeting. Our approach to time management affects the whole process of the negotiation, i.e. the commencement of the negotiation, keeping to the timetable of the negotiation, setting of binding deadlines, the decision making process, etc.

Punctuality is the politeness of kings, but the duty of Czech people. As Central Europeans we are expected to show up on time for the meeting. In many countries, time is valued more than in ours. If we are late, we must at least call the hosting party and apologize. A traffic jam is no excuse for being late. In the professional and business world, we receive visitors announced for a certain time in the order in which they have arrived. Receiving a known or more distinguished person out of the order is disrespectful to the other visitors. If we have arranged a meeting with a foreign guest or an important visitor, we always take care to reserve more time. In some cases, the guest needs a badge to enter the building or the parking lot.

Czech business people and entrepreneurs should always arrive at meetings or negotiations on time and thus show respect to their partner. It is inadmissible, however, to scold members of different cultures for their different approaches to time. Differences are also apparent in the approach to participation in social events. In some cultures, it is common to arrive on time, in some it may be even an hour after the announced beginning. In all cultures there may, of course, be individuals with a totally different, atypical behavior and approach to time. Even in the Czech moderately monochronic society, it is becoming evident that more often than ever time is money, so most of our business people should profess a time approach more similar to that of the Northern regions than that of the South.

Before the negotiation begins, it is essential to determine among others: the number of negotiators and their hierarchical rating. The number of people on both sides should be about the same. Czech negotiators tend to ignore that outnumbering from the side of the home party is considered as an unfair tactics of applying pressure. The hierarchical rating should also be equivalent on both sides. Foreign partners will strive to be received at the highest level possible. The home party may indeed offer reception on a higher level, however, never on a lower one. The negotiation itself is, nevertheless, carried out between people on the same professional and functional level in the hierarchy. Attention should also be paid to the meeting rooms themselves.

The secretary or a secretariat should always be informed regarding any expected visits. It is also often through the secretary that we arrange meetings. Important visitors should be expected and accompanied by somebody at the entrance or reception desk, for example by a junior employee or a secretary. They greet the guest orally or with a smile, they do not themselves, however, extend their hand for a handshake, which is often the case in the Czech Republic. They accompany the guest through the building, always give preference to the guest (regardless of whether they are a man or a woman) and attend solely to the visitor. They never deal with any other problems on the way or chat with other employees. They also 
take care of any overcoats or accessories of the guest, announce the visitor and introduce him into the meeting room or the host's office.

The host (be it man or woman) always stands up to welcome the guest, in our conditions most often with a greeting and a handshake. The host always comes forward to meet the guest - it is impolite to extend one's hand for a handshake over the table - and offers the guest a seat before sitting down himself. The host should not be sitting at his working table. It is more appropriate to lead the negotiation at a conference table (with the guest sitting at the right hand side of the host) or a negotiating table so that both parties (and their teams) are sitting opposing each other. A suitable seating plan should be conceived in advance. If more people are to be included in the negotiation, both the host and the guest must introduce them, provide their names as well their functions and the reason for their participation in the negotiation.

Briefcases, attaché cases and handbags are never placed on the table; their owners put them on the floor next to themselves. Women may also hang their handbags on the backrest of their chair or place them on the chair behind themselves. We never transport documents related to the meeting in plastic bags, shopping bags, sports bags or backpacks.

The host usually offers some refreshment. The array of refreshment is chosen by the secretary who also serves it to the guests. Apart from some exceptional cases, alcohol is not served during professional meetings in our conditions.

It is the host who signals the end of the meeting. It is also the host who says goodbye to the guest. An employee of the secretariat hands their overcoats and accessories to the visitors. If the guest is an elderly person or a person with limited mobility, we offer help. Assisting a woman with her coat is not accepted in the same way in all countries - in some it may cause resentment. The guest leaves alone or accompanied by a designated employee.

\section{The attire}

The attire reflects the personal taste, the purpose, place and time of the meeting. This part of social interaction can be prepared entirely before the negotiation or social event. Despite the casualness trend of today's fashion, some rules still apply - especially in the professional context. Some of the most frequent "faux pas" in the area of attire committed by Czech manages are, for example, wearing of slippers at the workplace, wearing of men's sandals without socks with a suit, unbuttoned top buttons of a shirt together with a loosened tie etc. The hands are not to be placed in the pockets. Chewing gum is inadmissible during meetings. The most criticized issue is the blowing of one's nose, in which case it is necessary to leave the room.

Our managers often choose inappropriate attire not only for meetings but also for social events. T-shirts or other items of clothes with marketing mottos or slogans are not acceptable for company events or for the workplace. Abusiness negotiation or an evening event with somebody whose chest is adorned with some company or product name or even animal pictures lacks credibleness. Even sports shirts or shirts with flashy colors or patterns are not suitable. Not to mention that parkas, leather jackets and wadded jackets do not work well with a suit. When walking, the top button of a single-breasted jacket should be buttoned; double-breasted jackets should be buttoned up. When sitting, only the bottom button may be unbuttoned in case of the double-breasted jacket. Wearing the suit jacket unbuttoned is inappropriate, however popular in our country. A suit also doesn't look its best with stuffed pockets or if the trousers are too short or too long. Czechs have trouble with shoes. Shoes to go with a suit must be made of leather, have a thin sole and always be of a darker shade than the suit itself. Evening suits are not combined with brown shoes. Men seem to be criticized by foreign partners for faulty or inappropriate attire more often than women. Czech women, on the other hand, are often praised for their good taste in dressing.

\section{Social events}

Every social event requires organization and preparatory work reflecting its importance, the number of people attending and the form of organization. Most guests, especially foreigners, will appreciate a well-organized meeting or social event. Some social events require invitations to be sent out; others will do with an oral invitation or an invitation letter. The absolute rule all around the world is that we never show up uninvited. Invitations should be sent out up to a month in advance, which is often neglected in our country. In many countries, people automatically excuse themselves from events if the invitation is sent at the eleventh hour. If we cannot avoid a last minute invitation, e.g. on the day of the event, we must ask the invitee to attend personally (possibly over the phone). With a few exceptions, invitations are usually non-transferable (a common mistake in our country). A seating plan must be designed for a gala, formal luncheons or dinners. The way guests are seated shows how much importance their host assigns to each of them. In the Czech Republic, we tend to have problems 
with understanding of abbreviations commonly used in invitations all over the world. Various types of social events differ from each other; many of them have common traits according to the occasion, customs of the country, etc. The most frequent social event in the business and entrepreneurial sphere, especially in the Czech Republic, seems to be the business lunch. The global trend is for business lunches to become shorter and, more often than not, no alcohol is served or offered (unlike in the Czech Republic). It is in fact little more than a business meeting; abroad it often takes place at the workplace itself(e.g. in a lounge). It is necessary to arrive on time for a business lunch. The meal tends to be more frugal than in the case of a dinner. In some countries, unlike ours, business lunches are not as popular. Despite their hospitality, some cultures e.g. the Japanese and the Chinese, dedicate the day to work and mostly invite their business partners for a banquet after business hours or towards the end of the day, i.e. around 5-6 P.M.

The way of ordering, preparing, and consuming food as well as even table manners differ from culture to culture. Getting a basic understanding of the customs of our foreign guests will make it easier for us to comprehend their behavior and their requests as well as enable us to cope with our role as the host. Guests from certain countries avoid eating pork, pork products or alcohol; others should not be offered beef. Yet others abhor dairy products and cheese. Asians eat their soup mostly in the morning, we eat it at lunch and most others prefer their soup in the evening. In some countries, national dishes include dog meat, frogs, turtles, and cats; in some others, they serve raw meat which is still warm. Game meat should only be served to Europeans. Some cultures eat with their hands (right hand only), some eat with chopsticks, others use cutlery. If hands are used, bowls filled with water, slices of lemon or fresh herbs and ice are placed on the table for rinsing of hands.

Nowadays, we do not have to finish our meal anywhere in the world; in some countries this is actually never the case as we would be signaling to the host that we have not had enough. In Europe we consider loud eructation after a meal rude; however, in many Asian countries, it is considered a tribute to the host. Guests should never be eating alone, it is always the host who starts to eat first and finishes their meal last and thus determines the pace of the meal. Personal life and professional life are mingled in many countries (e.g. Arab, Latin American). Meetings often take place at somebody's home; more often than in our country they may include e.g. an invitation to dinner at somebody's place. In these territories it would be a great mistake to reject such an invitation. However, an invitation to somebody's home does not mean that we should opt for casual or even homely attire.

\section{Exchanging of gifts}

Exchanging of gifts is considered a friendly gesture to further advance the relationship. Presents are often sent on the occasion of state holidays, New Year, birthday, company anniversary, etc. with a business card, or business cards in case of a shared present, enclosed to it. Naturally, the traditions regarding what kind of gift is acceptable, in which form it should be presented and how to repay the favor differ; inexperienced gift givers are always prone to a certain risk. We can say that generally, gifts are exchange more often when the relationship is based more on personal contact and mutual trust. In Asian, Arab and Latin American countries establishing of cooperation or the signature of a contract can hardly be imagined without the exchange of a rather costly present and an eventual faux pas may have a pretty unpleasant impact on the overall outcome of the negotiation. Europeans are more reserved in this sense. When invited to our partner's home we should send the hostess some flowers and bring a present for both the host and the hostess. In many countries you should even bring a treat or at least some sweets for their children. When in doubt what to give to foreign business partners, it is always good to choose something relevant to your country - especially high quality local products with a good reputation in the world. Most authors indicate that alcohol is not a suitable present. However, practice shows that (apart from Muslim countries) alcohol makes part of many gift items. Times change and nowadays alcohol is permissible even as a present between women. It should, however, be of high quality. As to the time and place of exchanging gifts, different rules apply in different countries. In most European countries, it is polite to unwrap the gift; in Asia, on the other hand, gifts are never unwrapped in the presence of the giver.

\section{Managerial implications}

It is safe to say that the Czech Republic has gone a long way in this area over the last decade despite some persisting deficiencies. Business people and managers have come to appreciate the importance of abiding by the rules of business protocol and realize that it is in their own interest. Practice shows that the knowledge of business protocol and adhering to its rules enables business people and managers to achieve smooth and swift advances along their career path. The mere knowledge of these rules unaccompanied by other skills indispensable for professional growth is not enough. Apart from their reliable 
appearance, perfect manners and fitting attire, a business person will hardly amaze their partner unless they profess due education in the sphere of their activity. Business protocol should, thus, be perceived as a kind of tool on the uncompromising battle field of business or even better, as an advantage to be used against those who underestimate it. The related surveys carried out show that in the Czech Republic we are more likely to encounter ignorance of the rules of etiquette and problems associated with inappropriate behavior and conduct when dealing with small and medium-sized companies. Ignorance of business protocol and of the differences in behavior of foreign partners is more common among new employees. Large enterprises often not only have in place mandatory codes of ethics and etiquette, but for several years their employees have also been undergoing various trainings and courses. The Czech state administration staff has also been trained in numerous courses. Some more experienced employees of large foreign companies tend to act in a patronizing way especially when dealing with smaller Czech companies and in some cases they may pinpoint their partners' shortcomings in the field of etiquette.

\section{References}

Archanelskij, M. D. (2002). Bisnis-etiket, ili igra po pravilam. Moskva: Eksmo.

Broddy, M., Pachter, B. (1994). Business Etiquette. New York: McGraw-Hill.

CGC (2007). Ellenbogenverhalten oder Sozialkompetenz - wie wichtig sind gute Umgangsformen bei Führungskräften?, (accessed March 19, 2012), [available at http://www.cgc-consulting.com/download/ UmgangsformenbeiFuehrungskraeften.pdf]
Gullova, S., Mullerova, F., Sato. A., Zamykalova, M. (2002). Obchodní jednání v zemích EU. 1.vyd. Prague: Univesity of Economics, Prague.

Gullova, S., Mullerova, F., Zamykalova. (2005). Problematika mezikulturních rozdílů v mezinárodním podnikání. Acta Oeconomica Pragensia, 15(2).

Gullova, S. (2011). Mezinárodní obchodní a diplomatický protokol. 2.vyd .Prague: Grada.

Guth-Jarkovsky, J. (1924) Pozdrav-společenské úvahy. Praha: Hejda a Tucek.

GFK (2006). Ergebnisse einer internationalen GfK-Studie zu Manieren der Europäer und US-Amerikaner, (accessed March 19, 2012), [available at http://www.gfk.com/imperia/ $\mathrm{md} /$ content/presse/pd_gfk_crww_studie_manieren_dfin.pdf]

Langford, B. A. (2005). The etiquette Edge: The Unspoken Rules for Business Success. New York: AMACOM.

Pernal, E. (2001). Taktně profesionálně elegantně. Prague : Ekopress.

Post, P., Post. P. (2005). The etiquette advantage in Business. New York: Collins Living. 